\title{
PENGUBAHAN BUNYI DALAM LIRIK LAGU BAHASA JAWA
}

\section{SOUND CHANGE IN JAVANESE SONG LYRICS}

\author{
Yerry Mijianti* \\ Pendidikan Bahasa dan Sastra Indonesia, Universitas Muhammadiyah Jember, \\ Indonesia \\ yerry.mijianti@unmuhjember.ac.id \\ *penulis korespondensi
}

\begin{tabular}{ll}
\hline Info Artikel & ABSTRAK \\
\hline Sejarah artikel: & Artikel ini ditulis dengan tujuan mendeskripsikan pengubahan bunyi dalam \\
Diterima: & lirik lagu bahasa Jawa. Data dalam penelitian bahasa ini adalah kata atau \\
25 Januari 2021 & frasa yang mengandung pengubahan bunyi bahasa Jawa. Sumber data \\
Direvisi: & adalah lirik lagu dari 41 judul lagu dalam enam album Video Compact Disk \\
21 Juni 2021 & Dangdut Koplo. Penelitian bahasa ini dilakukan dengan mengandalkan \\
Disetujui: & metode introspeksi dan metode simak untuk mengumpulkan data. Data \\
3 Juli 2021 & dianalisis dengan metode padan intralingual dan teknik hubung banding \\
& menyamakan atau disebut HBS. Teknik pengecekan keabsahan hasil \\
Kata kunci: & penelitian menggunakna teknik introspeksi. Hasil penelitian yaitu \\
pengubahan bunyi, lirik & pengubahan bunyi dalam lirik lagu bahasa Jawa meliputi empat hal yaitu : \\
lagu, bahasa Jawa & (1) pengubahan bunyi \{-ipun\} menjadi \{-nyo\} karena tuntutan guru lagu; \\
& (2) pengubahan secara sinkope, kontraksi, epentesis, dan paragoge karena \\
& tuntutan guru wilangan; (3) penambahan bunyi untuk mengindahkan dalam \\
& wujud puitisasi ragam; dan (4) informalisasi ragam dengan cara \\
& penanggalan suku pertama, penanggalan bunyi awal, penanggalan vokal/a/ \\
& pada \{-ake\}, penanggalan vokal /e/, penghilangan bunyi di tengah, dan \\
& pemendekan dalam frase.
\end{tabular}

\begin{tabular}{ll}
\hline Article Info & ABSTRACT \\
\hline Article history: & The aim of this article is describing sound changes in Javanese song lyrics. \\
Received: & The data in this language research are words or phrases that contain sound \\
25 January 2021 & changes in Javanese. The data source is the song lyrics from 41 song titles \\
Revised: & in the six albums of the Dangdut Koplo Video Compact Disk. This \\
21 June 2021 & linguistics research was conducted by relying on the introspection method \\
Accepted: & and scrutinize method to collect data. The data were analyzed by using \\
3 July 2021 & intralingual matching method and equalizing comparison technique or \\
& called HBS. The technique of checking the the research results validity uses \\
Keyword: & introspection techniques. The results of the study were sound change in \\
sound change, song & Javanese song lyrics covering four things, namely: (1) changing the sound \\
lyric, Javanese & \{-ipun\} to \{-nyo\} because of the demands of the song teacher; (2) changes \\
language & in syncope, contraction, epenthesis, and paragoge due to the demands of the \\
& sylablle; (3) sound addition to heed in the form of variety poetry; and (4) \\
& variety informalization use first syllable dismantlement, dismantlement the \\
& initial sound, dismantlement the vowel /a/ in $\{$-ake\}, dismantlement the \\
& vowel /e/, removing the middle sound, and shortening the phrase.
\end{tabular}




\section{PENDAHULUAN}

Bahasa dan musik sebagai hasil karya manusia yang tercipta dari interaksi antarpersonal dalam suatu masyarakat bahasa. Penutur bahasa yang memiliki beraneka macam pribadi saling berkomunikasi untuk menjalin suatu interaksi sosial. Komunikasi dalam interaski sosial tersebut dapat diabadikan menjadi lirik lagu. Lirik lagu yang didendangkan dengan musik yang nyaman didengar menghasilkan aktivitas bahasa. Penutur bahasa yang awalnya bermacam-macam menjadi satu macam dan memiliki sikap solidaritas ketika menikmati lirik lagu dalam sebuah jenis musik (Al Hafidz, 2020).

Lirik lagu berbahasa Jawa menjadi tren baru dalam kurun enam tahun ini (sejak tahun 2015 sampai tahun 2021). Pengamat musik Bens Leo menemukan ada enam sebab mengapa lagu-lagu berbahasa Jawa mendadak tren (Adikara, 2020). Keenam alasan tersebut, yaitu: (1) lagu dengan lirik berbahasa Jawa sering ditayangkan di televisi dalam kurun waktu tersebut; (2) orkes melayu selalu membawakan lagu berbahasa Jawa setiap tampil; (3) lagu dengan lirik bahasa Jawa mudah diterima oleh masyarakat karena menggunakan ragam percakapan; (4) lagu berbahasa Jawa memiliki harmonisasi yang baik antara lirik lagu dan melodi, (5) seniman daerah memiliki kemudahan memperkenalkan karyanya melalui media sosial, tak perlu mengikuti aturan standar di industri musik seperti pada masa sebelumnya, (6) generasi milenial (Generasi Y) dan Generasi Z sebagai penikmat lagu bahasa Jawa saat ini sedang menemukan hiburan baru yang unik dan khas.

Lirik berbahasa Jawa dikemas dengan lagu koplo Jawa. Sundari
(2020) mendefiniskan lagu koplo Jawa adalah lagu berbahasa Jawa yang dibuat dengan gaya lagu dangdut dengan sorakan di tengah lagu diiringi dengan kendang sebagai alat musik utama. Sejalan dengan Sundari, Raditya (2013) juga memiliki definisi dari dangdut koplo yaitu perubahan dalam bentuk, kualitas, dan sifat lain dari musik dangdut di wilayah pantai utara pulau Jawa yang dipadukan dengan seni musik kendang kempul khas Banyuwangi dengan memanfaatkan irama tradisonal seperti jaranan dan gamelan. Masyarakat kemudian mengenal dengan sebutan dangdut koplo. Genre musik ini sedang disukai masyarakat di Indonesia saat sekarang karena liriknya unik yang memadukan berbagai kosakata yang kaya dimiliki oleh bahasa Jawa, diiringi dengan banyak alat musik sehingga segala usia mampu menikmatinya.

Dangdut koplo yang mengusung bahasa Jawa sebagai media menyampaikan pesan dapat ditinjau sebagai usaha pemertahanan bahasa Jawa. Septiningsih (tanpa tahun) menemukan tiga alasan tentang penggunaan bahasa daerah dalam karya sastra, yaitu (1) untuk mengangkat budaya daerah sebagai tema karya sastra; (2) sebagai usaha mempertahankan bahasa daerah dari kepunahan; dan (3) sebagai dokumentasi yang dapat dijadikan rujukan dalam bahan ajar bahasa. Dangdut koplo sebagai budaya yang sedang populer saat ini mampu menarik minat orang muda tepatnya generasi Y (lahir tahun 1981-1994) dan generasi Z (lahir tahun 1995-2010). Hal ini sangat menguntungkan bahasa Jawa dalam hal ini bagian dari bahasa daerah yang digunakan untuk menuliskan lirik lagu (karya sastra) karena orang muda tetap menggunakan bahasa Jawa dewasa ini. 
Makin muda usia penutur suatu bahasa artinya makin lama bahasa tersebut dapat bertahan (Pangesti dalam Yulianto, 2020).

Pemilihan kosakata yang dituangkan dalam lirik lagu pada genre musik dangdut koplo tentu dilakukan dengan sangat cermat oleh pencipta lagunya. Para pencipta lagu yang notabene seniman ini tentu bukan ahli bahasa Jawa apalagi menguasai pembentukan kata atau proses morfologis. Namun, dengan mengandalkan intuisi kebahasaan mereka sebagai penutur asli bahasa Jawa, para seniman tersebut mampu menemukan kata-kata yang unik dan khas untuk dituliskan menjadi lirik lagu.

Proses pembentukan kata dalam bahasa Jawa masuk ranah Morfologi Bahasa Jawa. Morfologi bagian dari kajian linguistik. Kata-kata dalam bahasa Jawa berwujud morfem bebas dan morfem terikat. Morfem bebas dapat mengalami pengimbuhan (afiksasi), pengulangan (reduplikasi), pengubahan bunyi, pemajemukan (komposisi), dan penyingkatan secara akronim (Poedjosoedarmo dkk, 1979). Selanjutnya, Poedjosoedarmo dkk (1979) menyebutkan bahwa di dalam tembang (dalam hal ini disebut lagu) atau dalam puisi sangat memungkinkan penggunaan kata-kata yang dibentuk dari kata lain dengan melakukan pengubahan bunyi Pengubahan bunyi dilakukan karena tuntutan bunyi vokal pada akhir baris atau bait atau karena tuntutan penambahan jumlah suku kata pada sebuah baris atau bait. Penambahan atau pengurangan jumlah suku kata, penambahan atau pengurangan bunyi pada sebuah kata membuat kata-kata itu menjadi terasa lebih indah saat didendangkan (tembang atau lagu) atau dibaca (puisi).
Dengan demikian, pengubahan bunyi sangat berpengaruh terhadap lirik lagu khususnya lagu berbahasa Jawa. Pengubahan bunyi inilah yang banyak ditemukan dalam lirik lagu berbahasa Jawa tepatnya pada genre dangdut koplo. Genre yang sedang diminati orang muda saat ini.

Telah banyak penelitian tentang lagu berbahasa Jawa. Dua di antaranya dijelaskan berikut ini. Yang pertama ada penelitian dari Silowati (2009) yang mengupas wacana bahasa Jawa dalam sepuluh lagu campursari karya Didi Kempot. Penelitian tersebut menghasilkan: (1) terdapat kohesi gramatikal dan kohesi leksikal dalam lirik lagu karya Didi Kempot; (2) terdapat koherensi yang meliputi sebab akibat, konsesif, pertentangan, perbandingan, berhubungan dengan lokasi atau kala, contoh, dan penambahan; dan (3) ciri khas lirik lagu karya Didi Kempot yaitu menggunakan bahasa ngoko, tema kehidupan seharihari dan tema percintaan, dan mengungkapkan makna konotatif. Sedangkan yang kedua adalah penelitian karya Yulistiana dkk (2019) yang meneliti tentang diksi dan fungsi lirik lagu Tarlingdut karya Abdul Adjib dengan kajian stilistika. Hasilnya terdapat empat lagu menggunakan diksi estesis, diksi diambil dari serapan bahasa Jawa khas Cirebon, bahasa asing (Arab, Inggris, dan Cina), dan memanfaatkan sinonim.

Berbeda dengan kedua penelitian tersebut, penelitian ini membahas tentang pengubahan bunyi dalam lirik lagu berbahasa Jawa. Pengubahan bunyi yang dimaksud meliputi pengubahan bunyi guru lagu, pengubahan bunyi guru wilangan, puitisasi ragam, dan informalisasi ragam. Pengubahan bunyi tersebut sangat banyak terjadi pada kosakata 
yang digunakan dalam lirik lagu. Dengan demikian, masalah yang menjadi fokus kajian dalam penelitian ini adalah bagaimana pengubahan bunyi dalam lirik lagu bahasa Jawa. Selanjutnya, yang menjadi tujuan penelitian ini adalah mendeskripsikan pengubahan bunyi dalam lirik lagu bahasa Jawa. Masalah tersebut dipecahkan dengan memanfaatkan teori morfologis dalam bahasa Jawa miliknya Poedjosoedarmo dkk (1979).

Menurut Poedjosoedarmo dkk (1979) terdapat proses morfologi dalam bahasa Jawa yang membentuk kata dari kata dasar dengan mengubah satu atau beberapa bunyi vokal dan konsonan. Proses morfologi tersebut membentuk: (1) kata krama atau madya dari kata ngoko, (2) kata baru karena kebutuhan guru lagu, (3) kata baru karena tuntutan guru wilangan, (4) kata baru berdasarkan jenis kelamin, (5) kata baru karena informalisasi ragam, dan (6) kata baru karena puitisasi ragam. Proses pengubahan bunyi yang banyak ditemukan pada lirik lagu meliputi empat hal, yaitu (1) pengubahan bunyi guru lagu, (2) pengubahan bunyi guru wilangan, (3) puitisasi ragam, dan (4) informalisasi ragam.

Pengubahan bunyi guru lagu terjadi pada akhir baris atau akhir bait puisi atau lirik lagu. Guru lagu adalah variasi bunyi vokal pada akhir baris atau bait dari karya sastra berwujud puisi atau tembang (dalam penelitian ini disebut lagu). Bunyi akhir baris atau akhir bait harus berbunyi vokal tertentu agar terdengar lebih puitis. Poedjosoedarmo dkk (1979) mengelompokkan pengubahan bunyi karena tuntutan guru lagu meliputi tujuh bentuk, yaitu : (1) bunyi /o/ menjadi /i/, (2) vokal /i/ menjadi bunyi /yo/, (3) vokal /e/ menjadi bunyi /yo/, (4) akhiran $\{-e\}$ atau $\{$-ipun $\}$ menjadi $\{$-nyo $\}$, (5) vokal /i/ menjadi vokal /u/, (6) bunyi /oN/ menjadi bunyi /waN/, dan (7) vokal /e/ menjadi /a/.

Pengubahan bunyi guru wilangan merupakan pengurangan atau penambahan suku kata agar jumlah suku kata pada suatu bait sesuai dengan nada lagu. Guru wilangan adalah jumlah suku kata pada suatu bait sebuah karya sastra seperti puisi atau tembang. Sebuah kata yang memiliki jumlah suku terlalu banyak atau terlalu sedikit akan dikurangi atau ditambah agar sesuai dengan jatuhnya nada lagu. Poedjosoedarmo dkk menyebutkan bahwa terdapat empat macam pengubahan bunyi karena tuntutan guru wilangan, yaitu sinkope, kontraksi, epentesis, dan paragoge. Sinkope adalah penghilangan bunyi di tengah kata. Bunyi yang dapat dihilangkan misalnya /a/, /e/. /l/, /r/ atau /o/. Kontraksi adalah pemendekan atau penggabungan dua kata menjadi satu kata. Terdapat tiga pola kontraksi yaitu (1) $\mathrm{u}+\mathrm{I}=(\mathrm{w}) \mathrm{e}$, (2) o + i = e, dan (3) a $+\mathrm{a}=\mathrm{a}$. Epentesis adalah penambahan vokal atau sisipan pada sebuah kata agar memperpanjang bentuk kata atau jumlah suku kata. Paragoge adalah menambahkan bunyi /-ya/ pada suatu kata agar jumlah suku kata bertambah.

Puitisasi ragam merupakan pengubahan suatu kata agar terdengar indah atau terdengar puitis. Menurut Poedjosoedarmo dkk (1979) pengubahan dilakukan dengan menambah bunyi /a/ atau /ha/ di awal kata. Misalnya, jalaran $+\mathrm{a}=$ ajalaran dan mbangun + ha $=$ hambangun .

Informalisasi ragam merupakan pengubahan bunyi suatu kata dari bentuk formal menjadi bentuk informal. Pengubahan bunyi dilakukan dengan cara penanggalan, penghilangan, dan pemendekan. Informalisasi ragam dibedakan menjadi 
tiga belas macam menurut Poedjosoedarmo dkk (1979). Ketiga belas macam informalisasi ragam tersebut meliputi: (1) penanggalan suku pertama, (2) penanggalan bunyi awal, (3) penanggalan vokal /a/ pada sufiks \{ ake \}, (4) penanggalan vokal /a/ pada $\{\mathrm{ka}-\},(5)$ penanggalan vokal /e/, (6) penanggalan /i/ pada $\left\{\mathrm{di}^{-}\right\}, \quad(7)$ penanggalan $/ \mathrm{n} /$ pada $\{-\mathrm{an}\}$ dan $\{-\mathrm{mu}\}$, (8) penanggalan $/ \mathrm{k} /$, (9) penanggalan /r/, (10) penanggalan $\{$-um- $\}$, (11) penghilangan bunyi di tengah, (12) pemendekan dalam frasa, dan (13) penanggalan $\{\mathrm{di}-\}$.

\section{METODE}

Jenis penelitian ini adalah penelitian bahasa. Penelitian bahasa adalah kajian yang sistematis, terkontrol, empiris dan kritis terhadap bunyi bahasa (Mahsun, 2017). Sistematis maksudnya kajian dilakukan secara terencana dimulai dari identifikasi masalah, penyeleksian variabel dan instrumen, menghubungkan dengan teori linguistik, penyediaan, analisis dan interpretasi data sampai pada penarikan kesimpulan sesuai khazanah linguistik. Terkontrol artinya peneliti dapat melakukan pemilihan metode dan teknik yang sesuai dengan bunyi bahasa. Empiris dimaknai sebagai penggunaan fenomena yang sungguhsungguh terjadi dan digunakan oleh penutur bahasa. Kritis terhadap metode penyediaan data dengan melakukan revisi metode jika data yang diinginkan tidak segera ditemukan.

Data penelitian ini adalah kata dan frasa yang mengandung pengubahan bunyi. Sumber data penelitian ini berupa lirik lagu yang muncul pada teks di layar bagian bawah pada tayangan video musik. Video musik diambil dari enam album meliputi tiga album yang direkam oleh Perdana Record, satu album direkam oleh Milady Record, satu album direkam oleh Genta Record, dan satu album direkam oleh Danendra Suara Abadi. Keenam album tersebut masing-masing berjudul Via Valen the Best Ayah (2018), Lagista The Best Nella Kharisma (2018), Aurora Versi NDX AKA (2016), Duta Nirwana Musik Nella Kharisma (2017), OM Sera Live Show (2017), dan OM Sera Vol 2 (2018). Dari keenam album tersebut ditemukan ada 41 judul lagu yang mengandung pengubahan bunyi pada lirik lagunya.

Penelitian yang dilakukan ini termasuk sinkronis yaitu mengaji bahasa Jawa dalam satu waktu tertentu. Jangkuan waktu tersebut mencerminkan kesungguhan peneliti. Kesungguhan peneliti terwujud pada lamanya waktu penelitian, yaitu sembilan bulan. Penelitian dimulai sejak April 2020 sampai Januari 2021.

Tahap penyediaan data dilakukan atas dasar sudut pandang peneliti terhadap diri ketika mengaji objek bahasa, yaitu peneliti meneliti bahasa ibu atau bahasa yang dikuasainya, dalam hal ini bahasa Jawa. Berdasarkan sudut pandang tersebut maka data dalam penelitian ini dikumpulkan atau disediakan dengan menggunakan metode introspeksi dan metode simak. Metode introspeksi adalah tata cara menyediakan data dengan memanfaatkan gerak hati kebahasaan karena mengaji bahasa ibu untuk menghasilkan analisis yang sesuai dengan tujuan penelitian (Mahsun, 2017). Peneliti memberdayakan intuisi kebahasaan saat mengumpulkan kata atau frasa yang mengandung pengubahan bunyi bahasa Jawa berdasarkan wawasan kebahasaan dan mengecek ketepatannya melalui pemeriksaan pada Kamus Bahasa Jawa 
atau disebut Bausastra Jawa. Metode simak adalah menyimak penggunaan bahasa secara tertulis (Mahsun, 2017). Peneliti menyimak dengan sungguhsungguh dan berulang-ulang tayangan video musik untuk mengumpulkan kata atau frasa yang mengandung pengubahan bunyi bahasa Jawa. Teknik dasar yang digunakan adalah teknik sadap. Teknik sadap digunakan untuk menyadap bahasa secara tertulis berupa teks berisi lirik lagu bahasa Jawa. Penyadapan dilakukan dengan mencermati secara audio dan visual dari lirik lagu yang ada pada teks di layar serta suara dari sang biduan saat mendendangkan lirik lagu tersebut. Teknik lanjutan yang digunakan dalam penelitian ini adalah teknik catat. Teknik catat dilakukan dengan mencatat hasil simakan dan penyadapan terhadap video musik berupa kata atau frasa pada lirik lagu yang mengandung pengubahan bunyi bahasa Jawa.

Berdasarkan uraian tersebut, maka cara penggalian data yang dilakukan peneliti yaitu: (1) menyimak video musik dalam enam album dangdut koplo; (2) mencermati secara audio berupa suara sang biduan saat mendendangkan lirik lagu dan mencermati secara visual dengan melihat teks yang ada di bagian bawah layar yang berisi lirik lagu; (3) mencatat kata atau frasa yang mengandung pengubahan bunyi;

mengelompokkan kata atau frasa sesuai dengan jenis pengubahan bunyi. Keempat cara tersebut peneliti lakukan secara berurutan sebagai langkah mengumpulkan data.

Sehubungan dengan teknik pengumpulan data di atas maka dibutuhkan intrumen pengumpulan data. Selain peneliti sebagai instumen kunci karena peneliti adalah penutur asli bahasa Jawa, peneliti tetap membutuhkan alat bantu dalam mengumpulkan data. Instrumen yang digunakan peneliti untuk mengumpulkan data meliputi VCD (Video Compact Disk), player, alat tulis, dan tabel pengumpulan data. VCD berupa album dangdut koplo berisi lagu-lagu berbahasa Jawa diputar di player. Alat tulis digunakan peneliti untuk mencatat kata atau frasa yang mengandung pengubahan bunyi. Tabel pengumpulan data digunakan peneliti untuk mengelompokkan jenis-jenis pengubahan bunyi yang ditemukan pada lirik lagu.

Mahsun (2017) mengemukakan bahwa terdapat dua metode yang dapat digunakan untuk menganalisis data, yaitu metode padan intralingual dan metode padan ekstralingual. Teknik analisis data dalam penelitian ini menggunakan metode padan intralingual dan teknik hubung banding menyamakan (HBS). Metode padan intralingual dilakukan peneliti dengan membandingkan kata atau frasa dalam lirik lagu dengan teori pengubahan bunyi bahasa sehingga memiliki makna dan hubungan yang jelas. Teknik hubung banding menyamakan (HBS) digunakan peneliti dengan menghubungkan kata dalam lirik lagu dengan Kamus Bahasa Jawa atau Bausastra Jawa sehingga bentuk yang ditemukan dapat dibandingkan dengan teori pengubahan bunyi bahasa sehingga sebuah kata atau frasa dapat berterima dalam pemakaian bahasa Jawa sehari-hari.

Berdasarkan uraian tersebut, maka teknik analisis data yang dilakukan peneliti dituangkan menjadi langkahlangkah berikut ini. Cara kerja peneliti untuk menganalisis data yaitu: (1) mencermati klasifikasi data sesuai dengan jenis pengubahan bunyi; (2) 
membandingkan kata atau frasa dalam lirik lagu dengan teori pengubahan bunyi milik Poedjosoedarmo dkk (1979); (3) menghubungkan kata atau frasa dalam lirik lagu dengan lema yang ada dalam Bausastra Jawa; (4) menemukan bentuk-bentuk kata atau frasa yang berterima dalam percakapan Bahasa Jawa sehari hari atau yang berterima dalam sebuah lirik lagu. Keempat cara kerja di atas dilakukan peneliti secara runtut sebagai wujud dari teknik penganalisisan data dalam penelitian ini.

Keabsahan hasil penelitian dapat dilakukan dengan penulisan kembali sumber yang diacu pada kegiatan analisis data (Djajasudarma, 2010). Sumber yang dimaksud adalah bukubuku tentang teori pengubahan bunyi dan makna leksikon sebuah kata. Peneliti melakukan penulisan kembali teori tentang pengubahan bunyi menurut Poedjosoedarmo dkk (1979) dan makna kata secara leksikon dari Kamus Bahasa Jawa atau disebut Bausastra Jawa dalam aktivitas analisis data. Selain itu, peneliti juga menggunakan teknik introspeksi. Teknik introspeksi adalah memeriksa data berdasarkan intuisi kebahasaan sebagai penutur asli bahasa yang sedang dikaji (Djajasudarma, 2010). Peneliti mengerahkan gerak hati untuk menentukan keabsahan hasil penelitian karena peneliti adalah penutur asli bahasa Jawa.

\section{HASIL DAN PEMBAHASAN}

Pengubahan bunyi bahasa yang ditemukan pada 41 judul lagu dalam enam album dangdut koplo meliputi: (1) pengubahan bunyi guru lagu, (2) pengubahan bunyi guru wilangan, (3) puitisasi ragam, dan (4) informalisasi ragam. Keempat temuan tersebut akan dipaparkan dalam subjudul-subjudul berikut ini.

\section{Pengubahan Bunyi Guru Lagu}

Pengubahan bunyi guru lagu terjadi pada akhir baris atau akhir bait puisi atau lirik lagu. Bunyi akhir baris atau akhir bait harus berbunyi vokal tertentu agar terdengar lebih puitis. Poedjosoedarmo dkk (1979) mengelompokkan pengubahan bunyi karena tuntutan guru lagu meliputi tujuh bentuk, yaitu : (1) bunyi /o/ menjadi /i/, (2) vokal /i/ menjadi bunyi /yo/, (3) vokal /e/ menjadi bunyi /yo/, (4) akhiran $\{-e\}$ atau $\{$-ipun $\}$ menjadi \{-nyo \}, (5) vokal /i/ menjadi vokal /u/, (6) bunyi /oN/ menjadi bunyi /waN/, dan (7) vokal /e/ menjadi /a/.

Dari ketujuh pola yang disajikan di atas hanya ditemukan satu pola yaitu pengubahan akhiran \{-ipun\} menjadi /nyo/. Pola tersebut tampak pada data berikut.

\section{Mugo biso selaminyo (PA-2.4.1)}

Kata selaminyo pada data di atas dibentuk dari kata salaminipun 'saklawase' (selamanya). Untuk memenuhi hitungan guru lagu, dilakukan pengubahan bunyi pada kata salaminipun. Kata salaminipun dengan akhiran \{-ipun\} diubah akhirannya dengan bentuk/-nyo/ sehingga menjadi kata salaminyo. Namun, di teks (lirik lagu) yang muncul di layar bagian bawah video musik ditulis selaminyo.

Selain mengacu pada teori di atas terdapat temuan pola baru dalam pengubahan bunyi berdasarkan tuntutan guru lagu, yaitu adanya pengubahan bunyi /a/ menjadi bunyi /è/. Pola tersebut ditemukan pada data berikut. 
Wis ora iso meneh ditambahi (KM-2.8.1)

Terjadi pengubahan bunyi /a/ menjadi /è/ pada kata manèh 'mbaleni koyo sing uwis' (mengulangi seperti yang telah lalu) menjadi kata menèh. Namun, pada teks ditulis meneh.

\section{Pengubahan Bunyi Guru Wilangan}

Pengubahan bunyi guru wilangan merupakan pengurangan atau penambahan suku kata agar jumlah suku kata pada suatu bait sesuai dengan nada lagu. Poedjosoedarmo dkk (1979) menyebutkan bahwa terdapat empat macam pengubahan bunyi karena tuntutan guru wilangan, yaitu sinkope, kontraksi, epentesis, dan paragoge. Keempat macam pengubahan bunyi atas tuntutan guru wilangan di atas ditemukan dalam lirik lagu bahasa Jawa.

Sinkope adalah penghilangan bunyi di tengah kata. Bunyi yang dapat dihilangkan misalnya /a/, /e/./l/, /r/ atau /o/. Penghilangan bunyi yang ditemukan adalah penghilangan bunyi /1/ misalnya tampak pada data di bawah ini.

\section{Tapi saiki kowe wani mbenjani janji (MR-3.1.3)}

Pengubahan bunyi karena tuntutan guru wilangan terjadi pada kata mbenjani. Bunyi /1/ di tengah kata pada kata mblenjani 'ora nuhoni enggone semayan' (tidak menepati janji) dihilangkan sehingga menjadi kata mbenjani.

Kontraksi adalah pemendekan atau penggabungan dua kata menjadi satu kata. Terdapat tiga pola kontraksi yaitu (1) $\mathrm{u}+\mathrm{I}=(\mathrm{w}) \mathrm{e}$, (2) o + i = e, dan (3) a $+\mathrm{a}=\mathrm{a}$.
Dari ketiga pola di atas yang paling banyak ditemukan adalah yang berpola $a+a=a$. Seperti tampak pada data berikut.

Rasah dipikir duwe bojo sing galak (DP-3.2.5)

Kata rasah pada data di atas sejatinya berbentuk dua kata yaitu kata ora dan kata usah. Frasa ora usah (tidak perlu) sebagai ragam percakapan memiliki pola ora (a) ditambah usah (a) setelah dipendekkan menjadi $\mathrm{r} a \mathrm{~s} a \mathrm{~h}$ (a). Jika ditulis sesuai pola tersebut maka or $a$ (a) + us $a$ h (a) = rasah (a).

Epentesis adalah penambahan vokal atau sisipan pada sebuah kata agar memperpanjang bentuk kata atau jumlah suku kata. Yang paling banyak ditemukan adalah penambahan vokal, dalam hal ini, vokal /e/ yang paling banyak ditambahkan pada sebuah kata. Misalnya, tampak pada data berikut.

\section{Kok ngerusak utekku (BDB- 3.3.4)}

Pengubahan bunyi atas tuntutan guru wilangan secara epentesis dilakukan dengan menambah vokal /e/ pada kata ngrusak 'mbubrah, nggawe rusak' (mengubah menjadi tak terpakai) sehingga menjadi kata ngerusak.

Paragoge adalah menambahkan bunyi /-ya/ pada suatu kata agar jumlah suku kata bertambah. Paragoge yang ditemukan pada lirik lagu bahasa Jawa tidak sesuai teori Poedjosoedarmo yaitu dengan menambahkan bunyi /-ya/ tetapi menambah vokal /a/ pada suku kedua dan menambahkan konsonan /n/ pada suku ketiga. Paragoge yang ditemukan berupa penambahan suku kata dengan konsonan /a/ dan /n/ pada kata mergi 'jalaran saka' (disebabkan 
oleh) menjadi kata mergani. Jika ditulis polanya adalah $m e r g i+/ \mathrm{a} /+/ \mathrm{n} /$ dan jika ditulis berdasarkan suku kata menjadi mer + ga + ni sehingga kata yang telah diubah bunyinya menjadi mergani. Hal ini tampak pada data berikut.

\section{Mergani tresno iki tak direstui ibuku (KeM-3.4.1)}

Pengubahan bunyi atas tuntutan guru wilangan dengan cara paragoge dilakukan dengan menambah jumlah suku. Kata dari dua suku kata pada kata mergi 'jalaran saka' (disebabkan oleh) jika ditulis polanya adalah mer + gi. Kata mergi ditambah dengan vokal /a/ untuk suku kata kedua, dan konsonan /n/ untuk suku kata ketiga. Jika ditulis polanya adalah mer + ga + ni $=$ mergani. Dengan demikian muncul kata baru yang terdiri dari tiga suku kata yaitu kata mergani.Penambahan ini dilakukan agar mampu menyesuikan dengan nada lagu.

\section{Puitisasi Ragam}

Puitisasi ragam merupakan pengubahan suatu kata agar terdengar indah atau terdengar puitis. Menurut Poedjosoedarmo dkk (1979) pengubahan dilakukan dengan menambah bunyi /a/ atau /ha/ di awal kata. Misalnya, jalaran $+\mathrm{a}=$ ajalaran dan mbangun + ha $=$ hambangun . Pengubahan bunyi untuk mengindahkan dengan menambahkan bunyi /a/ pada sebuah kata tampak pada data berikut.

\section{Amung bantal tak sayang- sayang (KC-4.1)}

Pengubahan bunyi yang terjadi pada data di atas adalah penambahan bunyi /a/ pada kata mung 'ora ana liyane' (hanya) sehingga menjadi kata amung.
Kata amung dianggap sebagai kata yang lebih indah daripada kata aslinya yaitu kata mung.

\section{Informalisasi Ragam}

Informalisasi ragam merupakan pengubahan bunyi suatu kata dari bentuk formal menjadi bentuk informal. Pengubahan bunyi dilakukan dengan cara penanggalan, penghilangan, dan pemendekan. Informalisasi ragam dibedakan menjadi tiga belas macam menurut Poedjosoedarmo dkk (1979). Dari ketiga belas macam informalisasi ragam tersebut ditemukan enam macam informalisasi ragam, yaitu: (1) penanggalan suku pertama, (2) penanggalan bunyi awal, (3) penanggalan vokal /a/ pada $\{$-ake $\}$, (4) penanggalan vokal /e/, (5) penghilangan bunyi di tengah, dan (6) pemendekan dalam frasa.

Informalisasi ragam dengan cara penanggalan suku pertama paling banyak ditemukan yaitu sejumlah 130 data. Dari 130 data tersebut terdapat satu penanggalan suku pertama yang paling banyak ditemukan yaitu sejumlah 96 data. Penanggalan suku pertama yang paling banyak ditemukan tersebut tampak pada data berikut.

\section{Apa ra kelingan (NA-6.1.1) Aku ra milah milih (GTR-6.1.1f) Kaku ra koyo mbiyene (MR- 6.1.1l)}

Ketiga data di atas menunjukkan penanggalan suku pertama pada kata formal (ragam baku) yaitu kata ora. Jika dipolakan berdasarkan suku katanya adalah o-ra. Jika suku pertama (o) ditanggalkan maka tinggal suku kedua (ra). Setelah ditanggalkan maka muncul kata baru yaitu kata ra. Kata ra menjadi kata ragam percakapan (informal). Baik 
ora maupun ra sama-sama bermakna tidak.

Informalisasi ragam dengan cara penanggalan bunyi awal dapat dilihat pada data berikut.

\section{Ngerti ngene mbok rabeni aku ora sudi (NdK-6.2.1)}

Kata rabeni pada data di atas berasal dari kata ngrabèni 'ngepek bojo' (menjadikan pasangan hidup). Kata rabeni dibentuk dari hasil penanggalan bunyi awal /ng/ dari kata formal ngrabèni. Akhirnya muncul bentuk baru yaitu kata rabeni untuk memenuhi kebutuhan nada lagu pada lirik tersebut.

Informalisasi ragam dengan cara penanggalan vokal /a/ pada $\{$-ake $\}$ tampak pada data berikut.

\section{Aluse pangucapmu nentremke atiku (NK-6.3.5)}

Kata nentremke pada data di atas merupakan hasil pengubahan bunyi dengan cara penanggalan vokal /a/ pada akhiran $\{$-ake\}. Kata formal berwujud nentremaké 'ora duwe was sumelang' (tidak memiliki rasa khawatir) ditanggalkan bunyi /a/ pada akhiran \{ake \} sehingga berwujud kata baru yang berwujud kata informal nentremke. Kata nentremke dianggap tepat untuk memenuhi nada lagu pada lirik lagu tersebut.

Informalisasi ragam dengan cara penanggalan vokal /e/ dapat dilihat pada data berikut.

\section{Nanging kabeh iki ndang pengen cepet (P-6.5.1)}

Kata formal berwujud endang 'ènggal, rikat, agé' (segera) ditanggalkan vokal /e/ pada suku awal sehingga menjadi kata informal dengan wujud ndang.
Penginformalan ini dimaksudkan untuk membuat nada yang tepat pada lirik lagu tersebut.

Informalisasi ragam dengan cara penanggalan bunyi di tengah dapat dilihat pada data berikut.

Koe rep tak bojo ra mungkin dadi loro (CL-6.5.3)

Kata koe pada data di atas merupakan hasil pengubahan bunyi dari kata formal kowe 'panyebut marang wong sing diajak guneman' (sebutan untuk orang yang sedang diajak berbicara). Kata formal kowe ditanggalkan bunyi /w/ yang berada di tengah kata sehingga menjadi kata informal koe. Kata koe lebih tepat menempati lirik lagu tersebut karena menyesuikan jatuhnya nada.

Informalisasi ragam dengan cara pemendekan dalam frase tampak pada data berikut.

\section{Mencoba ra po po (BK-6.12.3)}

Kata ra po po pada data di atas merupakan hasil dari pengubahan bunyi dengan cara memendekkan bentuk formal sebuah frasa ora apa apa 'ora tatu' (tidak terluka). Kata ora apa apa dipendekkan dengan menanggalkan suku pertama tiap kata dalam frasa tersebut yaitu o dari o-ra, pa dari a-pa, dan pa dari kata a-pa. Kemudian terbentuk kata informal ra pa pa namun pada teks yang tampil di layar bagian bawah dari video musik yang tertulis adalah bentuk ra po po. Pemendekan ini dibuat dengan maksud agar jatuhnya nada tepat pada kata yang dipilih tersebut yaitu kata yang telah diubah wujudnya dari formal (ora apa apa) menjadi informal (ra po po). 


\section{PENUTUP}

Simpulan dari penelitian ini dijelaskan sebagai berikut. Pengubahan bunyi dalam lirik lagu bahasa Jawa meliputi empat hal yaitu : (1) pengubahan bunyi $\{$-ipun $\}$ menjadi $\{-$ nyo \} karena tuntutan guru lagu; (2) pengubahan secara sinkope, kontraksi, epentesis, dan paragoge karena tuntutan guru wilangan; (3) penambahan bunyi untuk mengindahkan dalam wujud puitisasi ragam; dan (4) informalisasi ragam dengan cara penanggalan suku pertama, penanggalan bunyi awal, penanggalan vokal /a/ pada $\{$-ake $\}$, penanggalan vokal /e/, penghilangan bunyi di tengah, dan pemendekan dalam frasa.

Saran yang dapat peneliti berikan adalah saran yang ditujukan kepada pembaca dan peneliti selanjutnya. Pembaca dapat memperkaya wawasan bahwa lirik lagu yang sering kita nikmati ini dihasilkan dari proses kreatif berbahasa dan bersastra. Dari hasil penelitian ini, pembaca dapat memahami bahwa pengubahan bunyi dari ilmu morfologi bahasa Jawa dapat dimanfaatkan untuk menciptakan karya sastra. Karya sastra berupa lirik lagu yang nyaman didengar dan mudah dipahami pendengar atau penikmat musik khususnya musik dengan genre dangdut koplo.

Peneliti berikutnya diharapkan mampu melanjutkan kajian tentang lirik lagu berbahasa Jawa dari sudut pandang ketidaktepatan penulisan kata. Berdasarkan temuan data banyak sekali ketidaktepatan penulisan kata dalam teks yang ditampilkan di bagian bawah layar dari seluruh video musik pada keenam album yang dikaji pada penelitian ini. Ketidaktepatan itu misalnya tampak pada penulisan wes, teko, dan dodoku. Tulisan yang tepat sesuai Bausastra Jawa adalah wis 'rampung enggoné tumindak' (telah selesai), teka 'wis bali manéh saka lelungan' (telah tiba dari bepergian), dan dhadhaku 'gembung sing ngarep sadhuwuré weteng' (bagian tubuh depan di atas perut). Jika tidak tepat menulis maka suatu kata akan dimaknai dengan cara yang berbeda. Misalnya, kata lara 'nandang ora kepénak ing badané (merasakan tidak nyaman di tubuh) dan kata loro 'wilangan sawisé siji sadurungé telu' (bilangan setelah satu dan sebelum tiga). Jadi, frasa lara ning ati (sakit hati) dengan loro ning ati (mendua) akan dimaknai berbeda karena penulisan lara dan loro dengan beda /a/ dan /o/ adalah dua kata yang berbeda makna.

\section{DAFTAR PUSTAKA}

Adikara, B. (2020, Januari 25). LaguLagu Berbahasa Jawa Mendadak Tren, Ini Enam Sebabnya. Retrieved April 30, 2020, from www.jawapos.com.

Al Hafidz, I.R. (2020, April 11). Terjadinya Akulturasi Bahasa terhadap Lirik Lagu Musik Dangdut. Retrieved April 30, 2020, from kompasiana.com.

Aurora. (2016) Aurora Versi NDK $A K A$. Perdana Record.

Djajasudarma, T.F. (2010). Metode Linguistik : Ancangan Metode Penelitian dan Kajian. Bandung: Refika Aditama.

Duta Nirwana Music. (2017) Nella Kharisma. Milady Record.

Lagista. (2018) The Best Nella Kharisma. Perdana Record. 
Mahsun. (2017) Metode Penelitian Bahasa : Tahapan, Strategi, Metode, dan Tekniknya. Depok : Raja Grafindo Persada.

OM Sera. (2017) OM Sera Live Show. Genta Record.

OM Sera. (2018) OM Sera Vol 2. Danendra Suara Abadi.

OM Sera. (2018) Via Vallen The Best Ayah. Perdana Record.

Poedjosoedarmo, S. dkk. (1979) Morfologi Bahasa Jawa. Jakarta: Pusat Pembinaan dan Pengembangan Bahasa, Departemen Pendidikan dan Kebudayaan.

Raditya, M. (2013) Dangdut Koplo : Selera Lokal Menjadi Selera Nasional. Retrieved April 30, 2020, from journal.unnes.ac.id

Septiningsih, L. (tanpa tahun) Pemertahanan Bahasa Daerah Melalui Penggunaan Bahasa Daerah dalam Karya Sastra. Retrieved April 30, 2020, from badanbahasa.kemdikbud.go.id.

Silowati, M. (2009) Wacana Bahasa Jawa dalam Sepuluh Lirik Lagu Campursari Karya Didi
Kempot (Suatu Tinjauan Kohesi dan Koherensi). Skripsi. Retrieved April 30, 2020, from digilib.uns.ac.id.

Sundari, R. (2020, March 20) 23+ Lagu Jawa dengan Berbagai Ragam, dari Tembang Macapat hingga Koplo! Retrieved April 30, 2020, from keepo.me.

Tim Balai Bahasa Yogyakarta. (2011) Kamus Bahasa Jawa (Bausastra Jawa) Edisi Kedua. Yogyakarta: Kanisius.

Yulianto, W.E. (2020, March 3). Revitalisasi Bahasa Terselubung Ala Budaya Pop. Retrieved April 30, 2020, from www.terakota.id.

Yulistiana, E., Sumarlam, Satoto, S. (2019) Diksi Lirik Lagu Tarlingdut Karya Abdul Adjib : Kajian Stilistika. Vol 5 No 1 April 2019 hlm 53-62 Retrieved April 30, 2020, from ejournal.umm.ac.id. 